\title{
Experimenting With Undergraduate Practicals
}

\begin{abstract}
Summary
In my experience the prescriptive nature of many undergraduate practicals restricts the scope for students to apply and develop their subject-specific knowledge. In addition, the nature of such practicals places limitations on their effectiveness for development of problem solving, team working and transferable skills. In recognition of this, a number of laboratory practicals in physical chemistry have been developed (some from existing traditional scripts) which feature clearly formulated and explicit objectives, but which omit detailed instructions to a greater or lesser extent. One particular aspect of these practicals is that the onus is placed on students to design a viable experimental approach in order to achieve the stated objectives and to reflect critically on their work. In this respect some of the practicals may be considered as structured mini-projects. Another implicit aspect is an attempt to encourage students to de-compartmentalise their subject knowledge (e.g. organic mechanisms in a 'physical' chemistry practical).

The practicals have been used successfully at levels 1 and 2 during the past two years at Keele, and although the approach described has been applied to laboratory work in physical chemistry, there is no reason why it cannot be applied more generally.
\end{abstract}

Subject area: Physical Science

\section{Description}

Laboratory practicals in physical chemistry:

(1) The Influence of Ionic Strength on the Rate Constant for the Reaction of Crystal Violet with Hydroxide ion (Level 2)

- Establish the rate law for the reaction.

- Determine the reaction rate constant over a range of ionic strengths.

- Establish whether the experimental results support the reaction mechanism by appropriate analysis of the experimental data.

- Suggest a molecular mechanism for the reaction.

(2) The Influence of Ionic Strength on the Solubility of Barium Iodate (Level 2)

- Determine the solubility product $\left(\mathrm{K}_{\mathrm{S}}^{\mathrm{O}}\right)$ for $\mathrm{Ba}\left(\mathrm{IO}_{3}\right)_{2} \cdot \mathrm{H}_{2} \mathrm{O}$.

- Determine mean activity coefficients $\left(\gamma_{ \pm}\right)$for $\mathrm{Ba}^{2+}$ and $\mathrm{IO}_{3}{ }^{-}$over a range of ionic strengths.

- Test the validity of the Debye-Hückel limiting law (DHLL).

(3) The Influence of Temperature on the Intensity of Chemiluminescence from Commercial Lightsticks (Level 1)

- Investigate the influence of temperature on the luminescence intensity of commercial chemiluminescent lightsticks and obtain the activation energy for the overall chemical reaction (figure 1). 


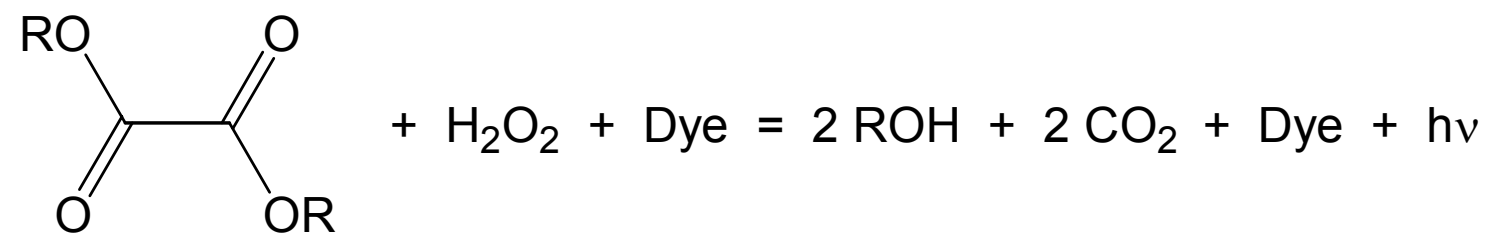

(Ox)

Figure 1 The overall chemical reaction that takes place in chemiluminescent lightsticks. Ox is an oxalate ester and the reaction is base catalysed.

\section{Type of activity}

The practicals are designed to provide experience with some, or all, of the following:

- Applying and developing subject-specific knowledge.

- Working effectively in a team.

- Planning your work.

- Designing, planning and carrying out an experiment.

- Learning from your mistakes.

- Plotting graphs and extracting information from graphs using Excel.

- Objective Information retrieval using the WWW.

- COSHH risk assessment.

- Recording and analysing experimental data.

- Use of chemical structure drawing packages.

- Use of online library catalogue.

- Locating a research paper in the Library.

- Extracting information from research papers.

- Critical reflection.

- Preparing and presenting a poster.
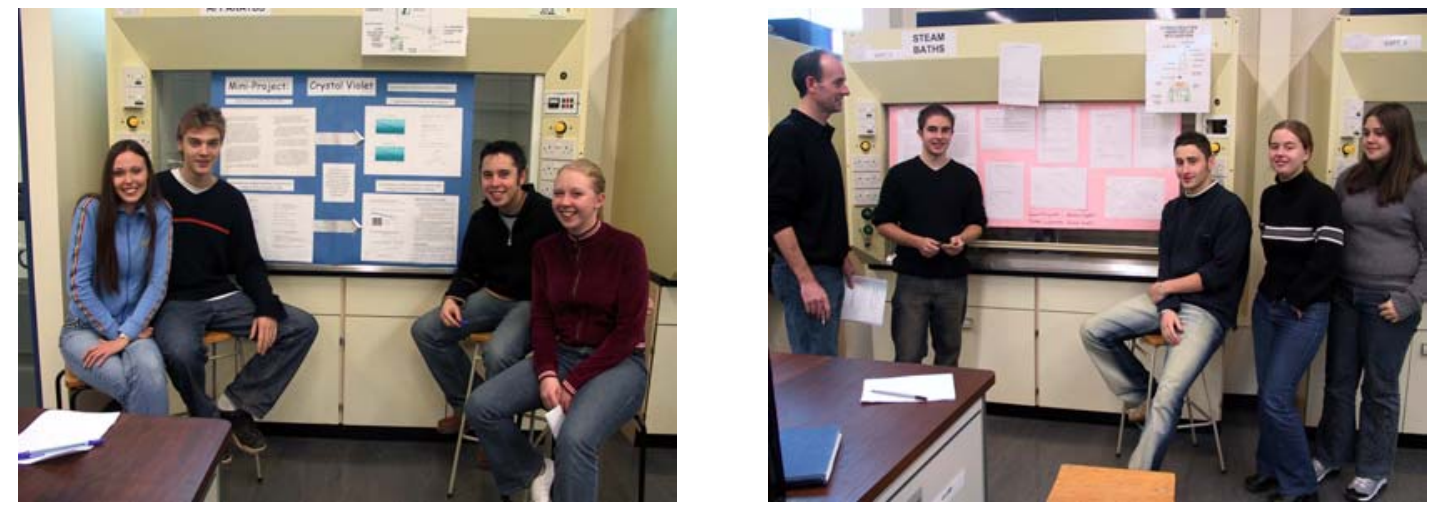

Keele University $2^{\text {nd }}$ Year Chemistry Poster Session, November 2002 

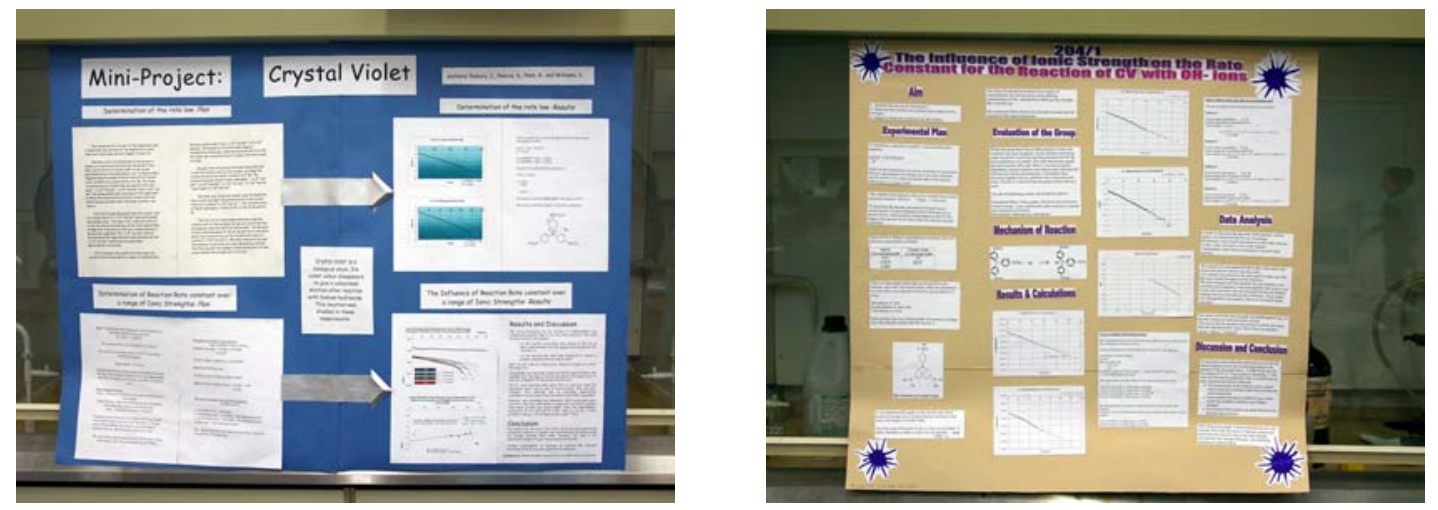

Keele University $2^{\text {nd }}$ Year Chemistry Poster Session, November 2002

\section{Content covered}

Chemistry: reaction kinetics, electrolyte solutions.

\section{Application}

The experiments can be used directly in undergraduate physical chemistry laboratory work. However, it is also envisaged that the approach can be adopted more generally for laboratory work in the sciences. More time may have to be allocated than for traditional practicals (e.g. perhaps 10 hours for the level 2 practicals) and it is more demanding (although arguably more stimulating) for demonstrators.

\section{Further comments}

Examples of the material are available via the LTSN website at www.physsci.ltsn.ac.uk in the Database of Practicals section. The author is happy to supply additional information if required or to discuss details with interested parties.

\section{Author(s)}

Dr David J McGarvey

School of Chemistry \& Physics

Keele University

\section{Contact details}

Dr David J McGarvey

Lennard-Jones Laboratories

School of Chemistry \& Physics

Keele University

Staffs ST5 5BG

Tel: 01782 584142; Fax: 01782 712378; E-mail: d.j.mcgarvey@chem.keele.ac.uk 